\title{
$O$ trabalho com o oral público no ensino médio: a apresentação oral em foco
}

Working with the public oral in high school: oral presentation in focus

Dorotea Frank Kersch

Universidade Vale dos Sinos - UNISINOS

Raquel Gonçalves de Oliveira

Universidade Vale dos Sinos - UNISINOS

DOI: https://doi.org/10.5902/2176148538721

Resumo: O ensino da oralidade vem ganhando espaço nos livros didáticos, na pesquisa e nas escolas, provavelmente impulsionado pelos documentos oficiais que orientam as práticas de linguagem na escola, inicialmente os Parâmetros Curriculares Nacionais e, mais recentemente, a Base Nacional Comum Curricular. O objetivo deste artigo é discutir como o trabalho com o gênero apresentação oral, desenvolvido na perspectiva de projetos, pode levar ao desenvolvimento do uso monitorado da modalidade oral da língua e promover a ampliação dos multiletramentos. No momento de seu ensino, os gêneros não podem ser vistos isoladamente, mas na sua interconexão com outros, em forma de rede.

Palavras-chave: Apresentação oral. Gêneros orais públicos. Multiletramentos.

Abstract:The teaching of orality has been gaining ground in textbooks, research and schools, probably driven by the official documents that guide language practices in schools, initially the National Curriculum Parameters and, more recently, the National Curricular Common Base. The purpose of this article is to discuss how the work with the oral presentation genre, developed from a project perspective, can lead to the development of monitored use of the oral language modality and promote the improve of multiliteracies. At the time of their teaching, the genres can not be seen in isolation, but in their interconnection with others, in the form of a network.

Keywords: Oral presentation. Public oral genres. Multiliteracies. 


\section{Introdução}

O ensino da oralidade vem ganhando espaço nos livros didáticos, na pesquisa e nas escolas, provavelmente impulsionado pelos documentos oficiais, correspondentes às práticas de linguagem, inicialmente os $\mathrm{Pa}$ râmetros Curriculares Nacionais - PCN (BRASIL, 1998) e, mais recente-

Dorotea Frank

Kersch

Raquel

Gonçalves de

Oliveira mente, a Base Nacional Comum Curricular - BNCC (BRASIL, 2018). Esse último documento estabelece que "o Eixo da Oralidade compreende as práticas de linguagem que ocorrem em situação oral com ou sem contato face a face" (BRASIL, 2018, p. 76), bem como a "oralização de textos em situações socialmente significativas e interações e discussões envolvendo temáticas e outras dimensões linguísticas do trabalho nos diferentes campos de atuação" (BRASIL, 2018, p. 77).

Pensando em "situações socialmente significativas" e "trabalho nos diferentes campos de atuação", foi levado a uma turma de nono ano de uma escola pública de Governador Valadares-MG um tema que se liga direta ou indiretamente a eles: as migrações para os Estados Unidos (o que os levou a pensar em outras migrações contemporâneas - venezuelanos, sírios, e brasileiros para outros países além dos EUA). Tudo começou com o desejo da professora da turma de trabalhar com um gênero oral que permitisse que o estudante fizesse um uso mais monitorado da língua. Assim se chegou ao gênero: os alunos fariam uma apresentação oral (elaborando slides que os apoiariam durante a apresentação) na Mostra Cultural que é organizada anualmente pela escola, ou seja, o trabalho realizado na sala de aula teria um fim social.

Marcadas pelo trabalho com Projetos Didáticos de Gênero - PDG (KERSCH; GUIMARÃES, 2012; GUIMARÃES, KERSCH, 2014 e 2015), partindo da realidade dos alunos - que têm no mínimo um familiar que está ou esteve nos EUA, pensamos em um projeto que trouxesse dados da realidade contemporânea - as migrações - para serem discutidos e estudados na aula de língua portuguesa.

Parece-nos que ensino dos gêneros orais sempre apresentou desafio para os professores, uma vez que a oralidade envolve uma série de outras questões (como voz, postura, gestos e olhares). Além disso, para uma apresentação oral, é necessário pesquisa, preparo, além, é claro, de uso da multimodalidade e de ferramentas digitais. Em relação à apresentação oral - gênero muito frequente na sala de aula, desde a escola básica até a pós-graduação -, Dolz et al. (2004, p. 215) destacam que a terminologia frequentemente utilizada na escola - o seminário - constitui ativi- 
dade oral praticada nas salas de aula, nas aulas de línguas, como também nas aulas de ciências, história etc. Os autores apresentam resultados de uma pesquisa com professores suíços de $6^{\mathrm{a}}$ série, os quais mostraram que $51 \%$ dos professores utilizam o seminário como atividade de expressão oral, perdendo apenas para atividades como leitura em voz alta (70\%), compreensão oral da narrativa (68\%) e compreensão de instruções e de manuais de instruções e de manuais de utilização (65\%). Na pesquisa, os professores revelaram que a exposição oral é a atividade mais útil para desenvolver o domínio da oralidade. Nesse sentido, pela sua complexidade, o gênero exposição oral precisa ser ensinado ao estudante.

De acordo com a BNCC, é papel do componente Língua Portuguesa "proporcionar aos estudantes experiências que contribuam para a ampliação dos letramentos, de forma a possibilitar a participação sig-

O trabalho com o oral público no ensino médio nificativa e crítica nas diversas práticas sociais permeadas/constituídas pela oralidade, pela escrita e por outras linguagens" (BRASIL, 2018, p. 65-66). Nessa perspectiva, este artigo tem como objetivo discutir como o trabalho com o gênero apresentação oral, desenvolvido na perspectiva de projeto, pode promover o desenvolvimento do uso monitorado da modalidade oral da língua, além da ampliação dos multiletramentos.

Este artigo acha-se dividido em cinco partes. Depois desta introdução, apresenta-se a base teórica que sustenta o estudo: os multiletramentos e os gêneros orais. Depois, descreve-se a forma de geração e análise dos dados. Na sequência, analisam-se e discutem-se os dados. Por fim, nas considerações finais, reforçamos, a partir da reflexão feita, o papel do professor na contemporaneidade

\section{Fundamentação teórica}

Nós agimos socialmente por meio de gêneros e textos. Nossas práticas de linguagem contemporâneas são caracterizadas por novos gêneros e textos cada vez mais multissemióticos e multimidiáticos. $\mathrm{O}$ acesso facilitado à tecnologia também abriu espaço a novas formas de produzir, de configurar, de disponibilizar, de compartilhar conteúdos e de interagir no mundo social, seja físico ou virtual. É papel da escola inserir o aluno para atuar com liberdade e de forma ética e responsável nessa configuração.

Estamos imersos em uma sociedade conectada, em que "o multiletramento, a multimodalidade e as redes sociais são palavras de ordem para a comunicação que ocorre em rede por meio de diversas linguagens digitais, tecnológicas, midiáticas, linguísticas, multiculturais e híbridas 
Dorotea Frank

Kersch

Raquel

Gonçalves de

Oliveira

em todos os sentidos na forma de se comunicar" (KERSCH; MARQUES, 2017, p. 346). Em tempos digitais, nossa forma de ler e escrever mudou radicalmente, assim como a forma como interagimos com os textos já não é a mesma. $O$ relatório do Fórum Econômico Mundial de 2015 apresenta uma visão diferenciada para educação ${ }^{1}$ e elenca habilidades consideradas necessárias para viver e atuar no séc. XXI: além dos letramentos e numeramento básicos, são necessárias a colaboração, a comunicação, a criatividade, a capacidade de resolução de problemas e de pensamento crítico, bem como qualidades de caráter, como persistência, curiosidade e iniciativa. Mercado e sociedade começam a ter demandas para as quais precisamos preparar nossos alunos que vão entrar nesse mercado mais adiante (que sequer sabemos que contornos terá). Esse relatório chama de letramentos fundamentais as habilidades que os alunos precisam para dar conta de atividades cotidianas. Ler e compreender textos e fazer cálculos básicos podia ser suficiente em outros momentos da história, mas hoje isso já não basta. Outros letramentos são necessários: o científico, o digital, o literário, o financeiro, o cultural e o cívico. Isso significa que a escola precisa acompanhar as mudanças contemporâneas, e ler, escrever e fazer cálculos são apenas o ponto de partida para o desenvolvimento dos letramentos necessários para agir socialmente e sobreviver neste século. Barton e Lee $(2015$, p. 17) afirmam que "estamos preparando estudantes para um futuro cujos contornos são, na melhor das perspectivas, nebulosos.", o que é fato. Afinal, a maioria dos empregos tradicionais de hoje provavelmente não existirão quando eles entrarem para o mercado de trabalho. Assim, não há como pensar em ensino hoje sem pensar em desenvolver também o letramento digital (ou letramentos digitais).

Essa reflexão nos mostra que, como mostram Kersch; Marques (2015), já não basta ensinar a ler e a escrever (a palavra impressa); é preciso desenvolver não só as capacidades de linguagem (DOLZ; PASQUIER; BRONCKART, 1993); tudo indica que os tempos atuais requerem que a escola desenvolva também capacidades que deem conta das multissemioses (ROJO, 2009, p. 105), ou seja, todas as formas de criar e produzir significado a partir das "possibilidades multimidiáticas e hipermidiáticas do texto eletrônico". Essas possibilidades são trazidas para o momento em que se lê, e elas precisam ganhar a sala de aula. Rojo (2009) diz que esses textos multissemióticos já ultrapassaram os limites

1 Disponível em http://www3.weforum.org/docs/WEF_New_Vision_for_Education.pdf, acesso em 05.07.2017 
dos ambientes digitais, invadindo e impactando também os impressos, como jornais, revistas, livros didáticos. Obviamente, no nosso caso, ao pensar em trabalhar com o gênero apresentação oral, temos de pensar nas características multimodais que se fazem presentes nesse gênero: ele é escrito para ser falado; imagens (ou mesmo vídeos), cores, gráficos são usados junto com o texto verbal para construir sentidos.

Além disso, uma apresentação oral efetivada na escola ou na universidade vai exigir pesquisa, avaliação crítica de informações, trabalho colaborativo, criatividade, resolução de problemas que forem se interO trabalho com o oral pondo; vai demandar também o planejamento do texto a ser apresentado, público no a comunicação escrita e, ao final, a comunicação oral; todas essas ações ensino médio vão levar à apropriação do gênero. Ou seja, trabalhar com um gênero como a apresentação oral na escola (e até mesmo na universidade) vai desenvolver muito mais que capacidades de linguagem, entre as quais incluímos as multissemióticas (KERSCH; MARQUES, 2015); vai contribuir para o desenvolvimento do letramento midiático crítico (KERSCH; LESLEY, 2019) dos alunos, o qual prevê a análise crítica da relação que há entre mídia, consumidores, informação (e sua veracidade) e as relações de poder que se estabelecem por meio da linguagem. Como bem observa Wolk (2003), “Os professores precisam ajudar seus alunos a pensar criativamente, a serem inovadores e a pensar por si mesmos, com o propósito de abrir novas possibilidades e restauração social" (p. 102). Ao discutir, na sala de aula, a realidade social em que os alunos se acham imersos, abre-se espaço para desenvolver cidadania e experimentar democracia.

Tudo isso nos leva a afirmar que, para se chegar a uma apresentação oral, uma série de operações são realizadas antes, e isso pode ser potencializado na aula de língua portuguesa (inclusive na sua relação com outras áreas). Vamos lançar nosso olhar especificamente nos gêneros orais e o que os caracteriza. Schneuwly (2004), ao tratar do ensino do oral na escola, afirma que

\footnotetext{
“Não existe 'o oral', mas 'os orais' em múltiplas formas, que, por outro lado, entram em relação com os escritos, de maneiras muito diversas: podem se aproximar da escrita e mesmo dela depender - como é o caso da exposição oral ou, ainda mais, do teatro e da leitura para os outros - como também podem estar mais distanciados - como nos debates, ou, é claro, na conversação cotidiana. Não existe uma essência mítica do oral que permitiria fundar sua
} 
didática, mas práticas de linguagem muito diferenciadas, que se dão, prioritariamente, pelo uso da palavra (falada), mas também por meio da escrita, e são essas práticas que podem se tornar objetos de um trabalho escolar" (SCHNEUWLY, 2004, p.135).

Dorotea Frank

Kersch

Raquel

Gonçalves de

Oliveira

Ou seja, o autor liga o oral fortemente à escrita. Aparentemente, o autor está se referindo ao verbal, mas acrescentaríamos aqui as multissemioses que caracterizam os textos contemporâneos. No caso dos gêneros orais que, inicialmente, são escritos para depois terem uma realização oral, eles vão abarcar também elementos característicos da língua oral (entonações, altura de voz, tom, etc.). Essas características tornam-se igualmente relevantes para o ensino de todo e qualquer gênero oral público. Tanto a fala quanto a escrita não são homogêneas e se dão num contínuo de variações, de modo que a carta se aproxima da conversa espontânea se levarmos em conta as estratégias de formulação textual que apresentam semelhanças e diferenças, ao passo que a conferência acadêmica se assemelha mais aos textos escritos do que com uma conversa espontânea.

Sendo assim, a relação oralidade e escrita não é óbvia nem linear, pois ambas refletem um constante dinamismo fundado num continuum que se manifesta entre essas duas modalidades de uso da língua, como destaca Marcuschi (1997). Dessa forma, não se pode dizer que são polaridades nem dicotomias que se esgotam, mas que normalmente há uma relação de interdependência entre elas, em se tratando de gêneros orais públicos. A conferência acadêmica, que, guardadas as diferenças, se aproxima da apresentação oral realizada pelos alunos,

é um gênero oral formal e público que apresenta complexas relações entre textos orais e escritos em sua elaboração e apresentação. Embora haja, em certos domínios de estudo e pesquisa, muitos conferencistas que redijam um texto que será lido em público, em nossa área, é mais comum o procedimento de se elaborar inicialmente um resumo e depois um arquivo num editor de apresentações (um "powerpoint" como se diz comumente), com slides, contendo esquemas; enumerações; definições ou citações; quadros, tabelas e gráficos; ilustrações e imagens, animados ou não. Sobre esses escritos, e em relação com eles, articula-se a fala do conferencista (ROJO e SCHNEUWLY, 2006, p. 470). 
Os autores destacam os passos dados pelo conferencista antes de "falar": o preparo da apresentação, a elaboração de resumo, a utilização de recursos de computador para edição de slides, os quais servem de suporte para a apresentação. Essas atividades complexas podem ser exercitadas com alunos na preparação de sua apresentação oral, em fases, de maneira que eles possam ir conhecendo o funcionamento desses gêneros que são escritos para depois serem falados, e consiga compreendê-los e produzi-los de acordo com as situações de interação em que vão se encontrar. 0 processamento textual falado ou escrito, segundo Marcuschi $(2007$, p. 196) “exige atividades que vão além da palavra, pois a construção de sentidos resulta da combinação de recursos visuais e verbais."

De acordo com Schneuwly (2004, p. 29), os gêneros primários O trabalho com o oral público no ensino médio acontecem em circunstâncias de uma comunicação verbal espontânea, e os gêneros secundários, como é o caso do gênero apresentação oral, "aparecem em circunstâncias de uma comunicação cultural, mais complexa e relativamente mais evoluída, principalmente escrita: artística, científica, sociopolítica." A exposição oral é um gênero secundário pela sua complexidade; os estudantes, ao se inteirar dele, dar-se-ão conta de que terão de se apropriar de novos conteúdos e de novas formas de expressão para que possam ser capazes de se colocar como sujeitos enunciadores no evento comunicativo em que usarão esse gênero.

Para organizar uma exposição oral, como se disse, o estudante fará uma preparação escrita do que ele vai falar em sua apresentação: terá de pesquisar e se aprofundar no assunto, em seguida, organizar as informações, agrupá-las, sumarizá-las para depois recompô-las em um novo texto. Depois dessas ações, vai compartilhá-lo com a audiência.

De certa forma, o trabalho com o gênero apresentação oral, como veremos adiante na análise, nos faz perceber que "o caráter multimodal e as facilidades de acesso às (novas) tecnologias demandam que os conceitos tradicionais de leitura e escrita - fortemente baseados na palavra e no impresso - sejam ressignificados, promovendo um diálogo entre o velho e o novo" (KERSCH e MARQUES, 2017, p. 193). Esse diálogo entre o velho e o novo, de que falam as autoras, pode ser percebido quando o estudante vai fazer pesquisas na internet, utilizar sites de busca, selecionar o que será estudado e navegar pelos ambientes digitais. Depois, na preparação da apresentação, ele vai utilizar recursos multimodais, como imagens, fotografias, animações e músicas. 
Dorotea Frank

Kersch

Raquel

Gonçalves de

Oliveira

Para o ensino do gênero apresentação/exposição oral, apresentam-se as fases sucessivas de sua consecução propostas por Dolz et al. (2004, p. 220): a abertura; a introdução ao tema; a apresentação do plano da exposição; o desenvolvimento e o encadeamento dos diferentes temas que se desdobram em subtemas relacionados ao assunto de acordo com o que foi apresentado no plano: a recapitulação e síntese; a conclusão; e o encerramento.

Esse gênero permite que se trabalhe com operações linguísticas que estabelecem ligações entre as partes do texto apresentado. Conforme Dolz et al. (2004, p. 222), as operações relacionadas à coesão temática, que articulam as diferentes partes (então, falaremos agora, é preciso...), ajudam a dar um caráter de boa elaboração à apresentação. 0 expositor deve sinalizar no texto a separação entre as ideias principais e as ideias secundárias (...sobretudo), assim como o desenvolvimento das conclusões e das sínteses (portanto...). Dolz et al. (2004, p.223) afirmam que "o domínio dessas operações depende bastante do uso de marcadores de estruturação do discurso" (então, portanto, sobretudo etc.); de organizadores temporais (então, no momento etc.); e dos tempos verbais", como por exemplo, tempo futuro (então, ao longo desta conferência, falarei primeiramente...). Há também a introdução de exemplos para legitimar o discurso (então, justamente, eu tenho o exemplo de...) e as reformulações (em forma de paráfrase ou definições) para explicar algum termo considerado difícil ou novo.

De acordo com Goulart (2017, p. 257), os expositores estabelecem com a audiência uma interação por meio de olhares, acenos de cabeça, gesticulam, sorriem, falam baixo ou com firmeza, dependendo do nível de desinibição. $O$ apresentador possui a liberdade de usar recursos materiais como cartazes, slides e Datashow, que dão suporte à memória dos expositores para que ordenem as suas falas e auxiliem a audiência a acompanhar o plano de exposição durante a apresentação. Para a autora, "a exposição oral pode ser um instrumento (ou megainstrumento) que favorece o desenvolvimento das capacidades linguístico-discursivas individuais dos estudantes de ensino médio" (2017, p.241), oportunizando-lhes, nas aulas de língua portuguesa, o processo de desenvolvimento da sua linguagem.

Em síntese, os gêneros, no mundo social, para cumprirem seu fim comunicativo, se conectam com outros gêneros, em forma de rede, o que faz com o que o trabalho com projetos seja muito adequado para esse caso. Essa forma de trabalho se presta muito para a complexidade que é ensinar a ler e escrever no séc. XXI. 


\section{Metodologia}

A pesquisa, com foco no ensino dos gêneros orais públicos, é qualitativa e interpretativista. Trata-se de uma pesquisa ação realizada por uma das autoras deste artigo (e orientada pela outra), quando a professora-pesquisadora concebeu e desenvolveu um projeto didático, cujo foco era o ensino do gênero apresentação oral. 0 trabalho desenvolvido guarda algumas características do Projeto Didático de Gênero - PDG (KERSCH; GUIMARÃES, 2012). Apesar de não ter seguido todos os passos daquele modelo didático, tinha foco no ensino de um gênero e tinha um objetivo final de fazer esse gênero ser usado para agir no mundo social.

A pesquisa foi realizada em uma escola da rede pública estadual do município de Governador Valadares - MG. Participaram da pesquisa os estudantes de duas turmas do terceiro ano do Ensino Médio, em que a professora-pesquisadora atuava. Os alunos - a maioria deles estavam na escola desde os anos iniciais - eram bastante participativos, e costumavam fazer as atividades propostas em sala de aula. Eram bastante agitados, mas demonstravam interesse pela aprendizagem. A faixa etária dos estudantes das duas turmas oscilava entre 16 (a maioria) e 20 anos.

O projeto didático desenvolvido consistiu na abordagem do tema da imigração da população de Governador Valadares para os Estados Unidos, problema vivenciado pelos moradores da cidade mineira e região desde final da década de 70 e que teve seu grande boom na década de 80. A partir de então, se instalou um fluxo migratório que alterou a rotina econômica e social do município. Todavia, o processo migratório teve movimento inverso quando muitos valadarenses retornaram ao Brasil a partir da crise internacional de 2008. Nesse período, muitos valadarenses perderam o emprego nos Estados Unidos, e a partir de 2010, voltaram à cidade para aproveitar o bom momento da economia brasileira daquele período.

Os moradores de Governador Valadares e região vivem as consequências desse processo de migração, pois algumas famílias estão divididas, com parte morando nos Estados Unidos e parte vivendo no Brasil. Na microrregião de Governador Valadares, em alguns municípios, $82 \%$ chegam a ter presença migratória, ou seja, pelo menos uma pessoa da família vive nos Estados Unidos. Em virtude disso, é pertinente tratar do tema da emigração dos valadarenses para os Estados Unidos, porque, como se disse, ela trouxe benefícios, contudo trouxe também problemas para a comunidade. Em alguns casos, entretanto, os estudantes nunca tinham parado para pensar sobre essa questão, que os afeta, direta ou indiretamente. 
As duas turmas participantes foram divididas em grupos, de maneira que cada um deles pesquisou um tema relacionado à emigração. Os próprios alunos sugeriram que cada grupo pesquisasse um tema para que os assuntos não se repetissem durante as apresentações. A ideia era que as apresentações fossem feitas para a escola toda e para as famílias que

Dorotea Frank

Kersch

Raquel

Gonçalves de

Oliveira viriam à Mostra Cultural que a escola realiza todos os anos em novembro. As pesquisas que redundaram em apresentação oral abordaram os seguintes temas: "Emigração dos valadarenses para os EUA"; "Imigração dos venezuelanos para o Brasil"; "Emigração dos brasileiros para o Japão"; "Imigração dos sírios para a Europa"; "Emigração dos brasileiros para Portugal"; "Migração e xenofobia"; "Migrantes e Refugiados" e "Migrações contemporâneas impulsionadas pela globalização". Desse último trabalho, foram gerados os dados discutidos neste artigo.

Os dados foram gerados a partir das produções dos slides dos alunos, gravações em vídeo e áudio das exposições orais dos grupos. Ao longo do desenvolvimento do projeto, foram feitas anotações em diário de campo das aulas e das atividades que iam sendo realizadas. As apresentações dos alunos foram transcritas, e, para isso, não se usou metodologia específica, não seguindo nenhum modelo de transcrição, atentando apenas ao conteúdo verbal, que nos interessava aqui.

Para compreender como o trabalho com o gênero apresentação oral, desenvolvido na perspectiva de projeto, leva ao desenvolvimento do uso monitorado da linguagem oral e promove a ampliação dos multiletramentos, vamos focar nas operações linguísticas realizadas pelos alunos no momento da apresentação oral, bem como nas estratégias multimodais de que lançaram mão para a construção dos textos, olhando para diferentes momentos: os slides em si, que são resultado da preparação dos alunos e a transcrição das falas dos alunos durante a apresentação.

\section{Resultados e discussão}

Da forma como os currículos estão organizados, um grande problema é o da compartimentalização dos saberes escolares. Uma alternativa para diminuir a fragmentação é valer-se de dispositivos didático-metodológicos como o PDG. O projeto desenvolvido, que guarda características desse modelo, teve, como vimos acima, o gênero apresentação oral como catalisador das atividades. 0 trabalho com esse gênero abre-se para um leque de perspectivas: oportuniza o trabalho colaborativo, desenvolve a criticidade (é preciso fazer escolhas quando se pesquisa, já que há muitas informações 
disponíveis) e a capacidade de comunicação, tanto escrita quanto oral, e os multiletramentos, como veremos na sequência. Iniciamos pelo slide 1 .

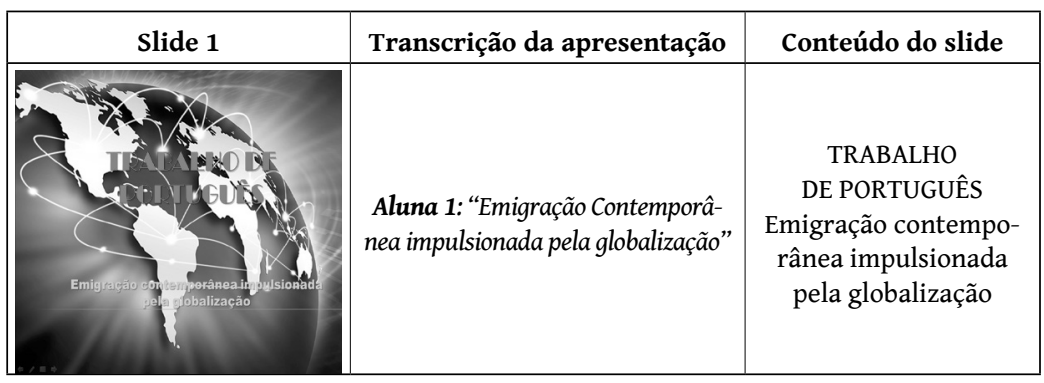

Fonte: Material da pesquisa das autoras

O clássico título "Trabalho de Português", que, em nosso tempo de escola, era estampado com letras desenhadas (e, muitas vezes, pintadas) na capa de um conjunto produzido em folhas de papel almaço, agora ganha o primeiro slide da apresentação também em letras garrafais, em tamanho maior que o próprio título do trabalho em si. Os dois títulos ganham cores diferentes, e o destaque parece ser mesmo para o 'trabalho de português', em cor vermelha. Parece que esse destaque faz parte de uma prática escolar que se mantém ao longo das décadas. Podemos ter passado do analógico ao digital, mas o "trabalho de português" se manteve, passando de uma geração a outra. Ainda que o maior destaque seja a esse título, quando as alunas iniciam a apresentação, o mencionado é apenas o 'subtítulo'. o pano de fundo escolhido para o slide demonstra a compreensão das alunas sobre o tema da globalização: o mapa múndi com as nações conectadas e com deslocamentos facilitados pelos meios de transporte, como veremos no slide 9 (Com isso, a facilidade de obter contato direto com o exterior, com isso também, o transporte, há um deslocamento por mais pessoas buscando melhoria de vida.). As alunas seguem a apresentação.

\begin{tabular}{|c|c|c|}
\hline Slide 2 & Transcrição da apresentação & Conteúdo do slide \\
\hline 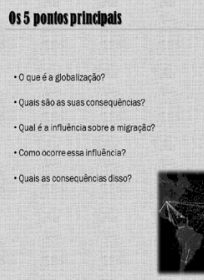 & $\begin{array}{c}\text { Aluna 1: "Aí a gente vai focar } \\
\text { em cinco pontos principais e } \\
\text { explicar cada um deles. O que é } \\
\text { globalização? Quais são as suas } \\
\text { consequências? Qual é a influência } \\
\text { sobre a migração? Como ocorre } \\
\text { essa influência? Quais são as conse- } \\
\text { quências disso?" }\end{array}$ & $\begin{array}{l}\text { Os } 5 \text { pontos princi- } \\
\text { pais: O que é globaliza- } \\
\text { ção? Quais são as suas } \\
\text { consequências? Qual é } \\
\text { a influência sobre a mi- } \\
\text { gração? Como ocorreu } \\
\text { essa influência? Quais } \\
\text { as consequências disso? }\end{array}$ \\
\hline
\end{tabular}

Fonte: Material da pesquisa das autoras
O trabalho com o oral público no ensino médio 


\section{Dorotea Frank \\ Kersch \\ Raquel \\ Gonçalves de \\ Oliveira}

432

Em relação às fases previstas por Dolz et al. (2004, p. 220), parece que as fases 1,2 e 3 (abertura, apresentação do tema e do plano da exposição) acabam acontecendo simultaneamente no slide 2 quando a aluna 1, olhando para o slides, diz "Aí a gente vai focar em cinco pontos principais e explicar cada um deles". O marcador discursivo "aí", bastante comum na oralidade para denotar sequência, parece ser usado para chamar a atenção da audiência para o que vai ser tratado; ao mesmo tempo em que se liga ao título, diz o que vai acontecer ao longo da apresentação: a explicação de cada um daqueles cinco pontos. Ou seja, cada gênero tem alguma flexibilidade: o fato de as alunas não terem feito uma saudação formal, não significa que não tenham conseguido ganhar a atenção da audiência. Seguimos a análise.

\begin{tabular}{|c|c|c|}
\hline Slide 3 & Transcrição da apresentação & Conteúdo do slide \\
\hline 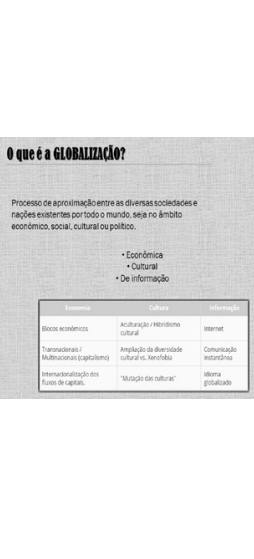 & $\begin{array}{l}\text { Aluna 1: "O que é globalização? } \\
\text { Quando a gente pesquisa, o que } \\
\text { a gente mais acha é: que é um } \\
\text { processo de aproximação entre } \\
\text { as diversas sociedades e nações } \\
\text { existentes por todo mundo, seja no } \\
\text { âmbito econômico, social, cultural, } \\
\text { Político. E aqui dei exemplos de } \\
\text { três mais falados: blocos eco- } \\
\text { nômicos, cultura, aculturação e } \\
\text { hibridismo cultural e informa- } \\
\text { ção que é o que a gente mais vê, } \\
\text { a internet." }\end{array}$ & $\begin{array}{l}\text { O que é a GLOBALIZAÇÃo? } \\
\text { Processo de aproximação } \\
\text { entre as diversas socie- } \\
\text { dades e nações existentes } \\
\text { por todo o mundo, seja no } \\
\text { âmbito econômico, social, } \\
\text { cultural ou político. } \\
\text { Econômica } \\
\text { Cultural } \\
\text { De informação } \\
\text { Economia Cultura Infor- } \\
\text { mação } \\
\text { Blocos econômicos/Acultu- } \\
\text { ração/Hibridismo cultural/ } \\
\text { internet }\end{array}$ \\
\hline
\end{tabular}

Fonte: Material da pesquisa das autoras

No slide 3, as alunas começam a cumprir a promessa feita no início, trazendo o conceito de globalização. A aluna 1 não se limita à leitura do slide, que traz um quadro provavelmente copiado de algum texto da internet ${ }^{2}$. Mesmo que assim seja, a aluna consegue articular o que está escrito no slide com o fio condutor de sua apresentação, procurando ela

2 Nossa experiência tem nos chamado a atenção para a necessidade de o professor, já na escola básica, acompanhar as "pesquisas" que os alunos fazem na internet. Tratar da questão da autoria e do plágio é de fundamental importância, desenvolvendo, desde cedo, uma atitude ética e responsável com os alunos, de modo que cheguem mais conscientes disso no ensino superior. Na verdade, essa prática também é histórica: em nossos anos de escolarização, a 'pesquisa' com que nossos professores eram coniventes, era, depois de colocar o título em letras garrafais na folha de rosto, copiar longos trechos das enciclopédias, e, não raras vezes, recebíamos nosso "trabalho de português" de volta com a "avaliação" visto. 
mesma responder à pergunta que está no título do slide: $\mathrm{O}$ que é a globalização? E aqui aparece sua voz "Quando a gente pesquisa, o que a gente mais acha é", lê o slide e volta à sua voz "E aqui dei exemplos de três mais falados. A aluna constrói a sua relação com a audiência, dizendo a fonte do conceito (a gente pesquisa) e, com o uso da primeira pessoa, se instaura como especialista. Aos três âmbitos "mais falados", são apresentados exemplos (blocos econômicos, cultura, aculturação e hibridismo cultural e informação). Como, de fato, explicar cada um desses exemplos, que são complexos, requereria um estudo mais aprofundado, ela resolve explicar o último (informação) ligando-o a algo provavelmente conhecido por ela e pela audiência (que é o que a gente mais vê, a internet.) O uso do pronome pessoal "a gente", desta vez, inclui o público que a ouve.

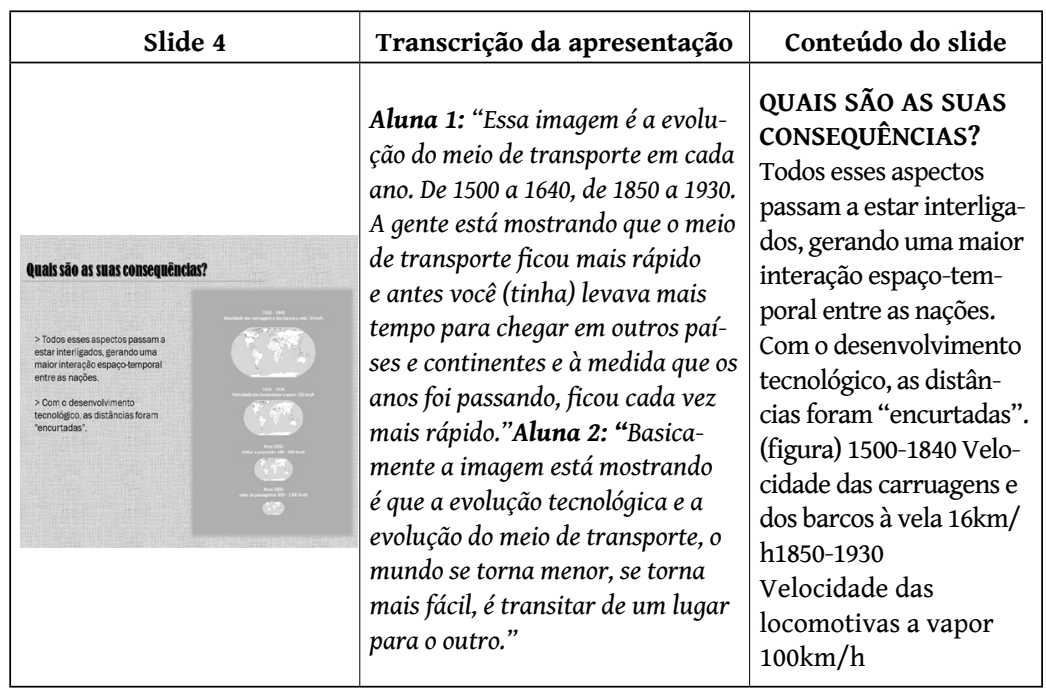

Fonte: Material da pesquisa das autoras

As alunas continuam construindo sentido com sua apresentação, seguindo a fase de desenvolvimento e encadeamento (DOLZ et al. 2004), a partir do plano delineado no segundo slide. Desta vez, elas não leem o título do slide, tampouco os tópicos elencados à esquerda. 0 primeiro deles apresenta um referente (todos esses aspectos) que não é explicitado (talvez sejam os exemplos usados para explicar os âmbitos em que as pessoas se aproximam). Mesmo assim, elas conseguem construir a coesão do que vêm argumentando, passando diretamente à explicação da imagem usada para mostrar como aquelas conexões da imagem de fundo no primeiro slide são possíveis: as distâncias foram sendo encurtadas à medida que o 


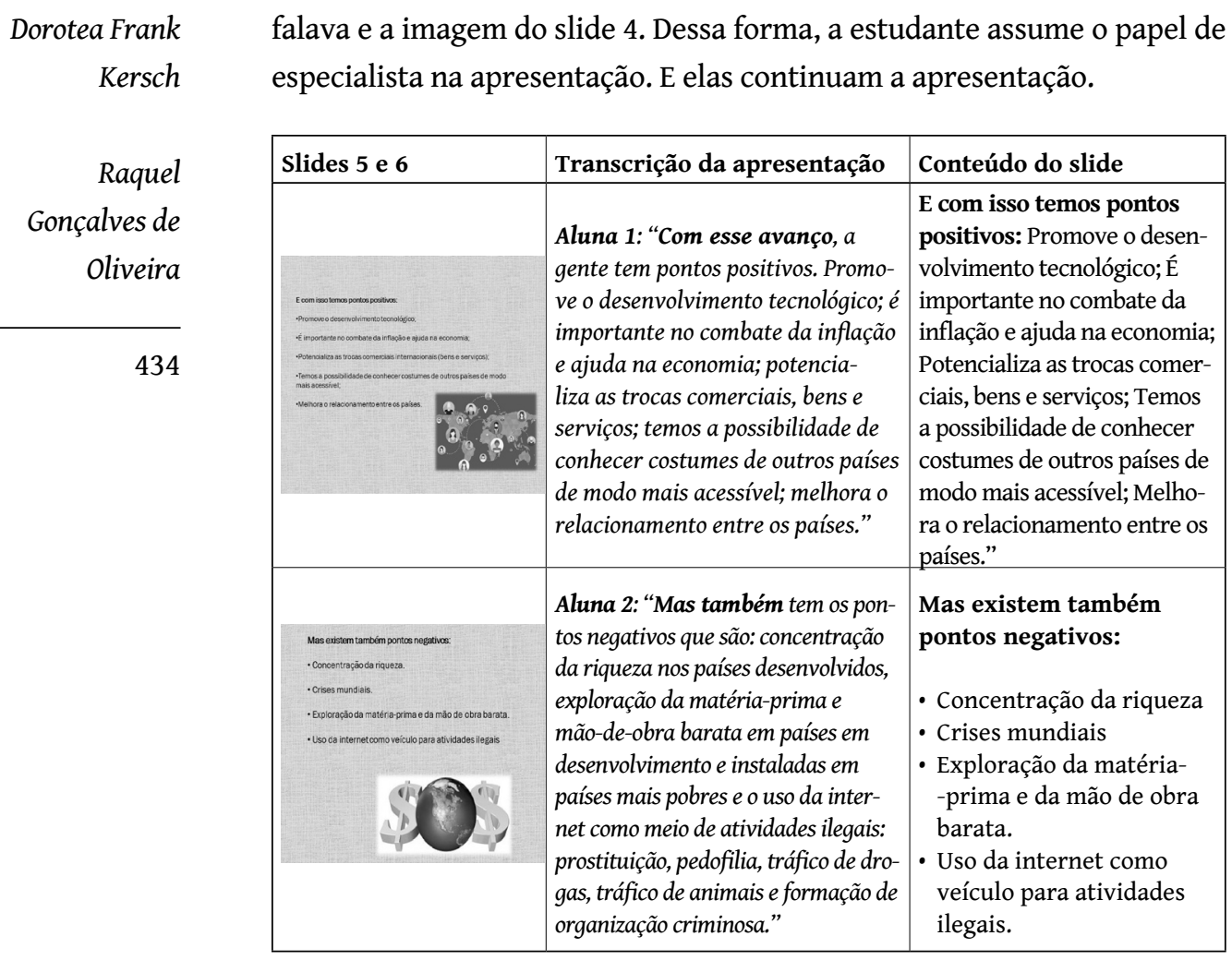

Fonte: Material da pesquisa das autoras falava e a imagem do slide 4 . Dessa forma, a estudante assume o papel de especialista na apresentação. E elas continuam a apresentação.

tempo que se levava para se deslocar de um ponto a outro do planeta foi sendo diminuído. Nesse ponto da apresentação, elas tomam a palavra de fato, e o uso de 'a gente' mostra isso. Pela primeira vez, a aluna 2 toma o turno para resumir a explicação da aluna 1 com o 'basicamente', que acaba exercendo a função de conector conclusivo, ligando o que a colega

As alunas seguem construindo a coesão e a coerência de sua apresentação, com a aluna 1 como protagonista. Ao usar o referente 'com esse avanço' (slide 5), em que retoma a questão da evolução dos transportes, que derrubou fronteiras, ela introduz o outro tópico - os aspectos positivos. Agora, sim, o conteúdo mostrado é lido. 0 slide apresenta imagem do mapa-múndi com as pessoas interligadas pela internet. As alunas continuam construindo sua argumentação e introduzem o slide seguinte com a contraposição: a apresentação dos aspectos negativos, cujo contraste é marcado adequadamente com o uso do conector "mas também", de certa forma parafraseando o título do slide 6. A aluna traz exemplos para o tópico "Uso da internet como veículo para atividades ilegais", com 
um vocabulário de certa forma elaborado. Analisando o diário de campo desse dia de apresentações, encontramos o registro de que "as alunas iam explicando e às vezes, olhavam o celular, revelando a relação oralidade e escrita, o dinamismo do continuum". (diário de campo, 24.11.2018)

Ou seja, registros no celular apoiaram a apresentação. $O$ slide também traz uma imagem que auxilia na construção da coerência do texto da apresentação. Os cifrões que ladeiam o planeta dão destaque aos aspectos econômicos da globalização e suas consequências nefastas, formando a palavra SOS, ou seja, a humanidade pede socorro.

O trabalho com o oral público no ensino médio

Fonte: Material da pesquisa das autoras

$\mathrm{Na}$ apresentação do slide 7, mais uma vez a tomada efetiva da palavra pelas alunas é característica do momento. Os tópicos do slide sobre miscigenação e aculturação são esclarecidos com exemplos do povo de sua cidade: a adoção do protestantismo dos valadarenses antes católicos, além de outros hábitos que mudam sua maneira de ser e viver ao voltarem a viver na cidade, o que legitima o seu discurso. Há, nesse trecho, uma série de marcas linguísticas que demonstram a apropriação de estilo de formalidade (oral culto) do gênero pelas alunas (acerca de...; por exemplo...; na qual...entre outras) e com essas marcas vão construindo a coesão e a coerência de seu texto. A imagem usada para ilustrar o slide mostra o globo terrestre com os principais pontos turísticos de alguns países, como a torre Eiffel da França e o Big Bang da Inglaterra, bem como alguns cumprimentos: hello, hi, bonjour e hola. 


\section{Dorotea Frank}

Kersch

Raquel

Gonçalves de

Oliveira

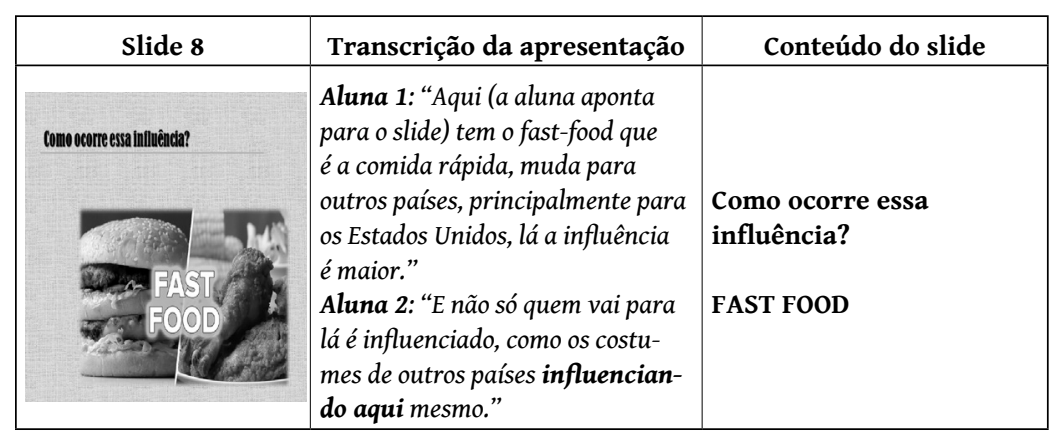

Fonte: Material da pesquisa das autoras

O slide 8, no título, traz o referente "essa influência", por meio do qual se liga ao anterior para explicar a questão da mudança de hábitos dos valadarenses, dando destaque ao fast-food. A aluna 1 explica o significado do termo; o "aqui" de sua fala refere-se ao slide. Ela destaca que a questão do fast-food é mais comum nos Estados Unidos, destino da maioria dos valadarenses. A aluna 2 ratifica a fala da colega, destacando as consequências disso para a cultura da cidade: esse hábito alimentar acaba sendo trazido para a cidade.

\begin{tabular}{|c|c|c|}
\hline Slide 9 & Transcrição da apresentação & Conteúdo do slide \\
\hline Quals as consequências disso? & $\begin{array}{l}\text { Aluna 1: “As consequências disso é } \\
\text { que quanto mais você tem acesso } \\
\text { a informações de outros países, } \\
\text { mais a gente quer conhecê-los né } \\
\text { e é raro alguém falar que não } \\
\text { visitaria a América do Norte, } \\
\text { mas devido a crise vivida em mui- } \\
\text { tos países, como: o desemprego, a } \\
\text { violência, baixa economia e alguns } \\
\text { casos, governos totalitários, hoje } \\
\text { a solução mais viável é migrar-se. } \\
\text { Com isso, a facilidade de obter } \\
\text { contato direto com o exterior, com } \\
\text { isso também, o transporte, há um } \\
\text { deslocamento por mais pessoas } \\
\text { buscando melhoria de vida." }\end{array}$ & $\begin{array}{l}\text { Quais as consequên- } \\
\text { cias disso? }\end{array}$ \\
\hline
\end{tabular}

Fonte: Material da pesquisa das autoras

O slide 9 tem apenas título e uma imagem, que apresenta os pontos turísticos principais de alguns países. Em seu texto oral, a aluna constrói um trecho bastante rico: para explicar as consequências dessa mudança cultural, ela inicia usando um articulador que indica proporcionalidade (quanto mais... mais) além de um pronome 
oblíquo (los) para retomar 'outros países'. o pronome oblíquo, marca da escrita culta, apresenta índices da apropriação do oral público pela aluna.

\begin{tabular}{|c|l|l|}
\hline Slide 10 & \multicolumn{1}{|c|}{ Transcrição da apresentação } & Conteúdo do slide \\
\hline & $\begin{array}{l}\text { Aluna 2:"Com a evolução tecnológica e a } \\
\text { evolução do meio de transporte, principalmen- } \\
\text { te a evolução tecnológica, a internet se tornou } \\
\text { um meio de persuasão, de tentar convencer a } \\
\text { pessoa de que aquela realidade é melhor que a } \\
\text { sua. Ou então, é mais fácil a comunicação por- } \\
\text { que pode fazer emigrações ilegais, ficou bem } \\
\text { mais fácil hoje em dia por causa da internet." } \\
\text { Aluna 1: "Duas consequências disso, } \\
\text { também é a xenofobia que é a aversão a } \\
\text { estrangeiro e hegemonia que é um país } \\
\text { que influencia todos os outros, no caso os } \\
\text { Estados Unidos, que tem grande influência, } \\
\text { muito forte, no mundo inteiro }\end{array}$ & Xenofobia \\
\hline
\end{tabular}

O trabalho com o oral público no ensino médio

Fonte: Material da pesquisa das autoras

O slide 10 vem com apenas duas imagens e um título sobreposto a uma delas: Xenofobia. O slide traz a imagem de um mapa-múndi estampado no rosto de um rapaz, caracterizando a xenofobia, e a outra imagem mostra a bandeira norte-americana entrelaçando o resto do mundo, representando a hegemonia dos Estados Unidos. Na construção do texto oral, as alunas citam a internet como 'ferramenta' de exclusão sob dois aspectos: por um lado, usada por uns para convencer outros de que sua cultura/realidade é melhor, e, pelo outro como facilitadora das imigrações ilegais. Não fica clara a relação com a evolução tecnológica e com os transportes (já aventada no slide 4). De certa forma, em sua explicação, a aluna revozeia o que foi falado por ela mesma no slide 6. Já a aluna 1 usa um referente (duas consequências disso) que não é claramente recuperado, e apresenta o conceito de xenofobia e a supremacia dos Estados Unidos, ambos retratados nas imagens usadas para construir o sentido. Nesse ponto, elas passam para as imigrações contemporâneas, título da apresentação. 
No último slide, com o mesmo título dos dois anteriores, as alunas fecham sua apresentação, destacando o âmbito que consideram estar na base de toda a discussão - o econômico. Da mesma forma como no início, este slide acaba servindo para a antepenúltima e penúltima fases - a recapitulação (A gente colocou as emigrações devido à economia) e a conclusão (a conclusão é). Não há encerramento explícito.

Percebe-se que a coesão temática que as alunas vinham construindo e mantendo até aqui é quebrada nesse último slide quando a aluna 2 traz os cinco países com mais brasileiros (que ela parafraseia com "onde tem mais brasileiros). 0 gráfico que é apresentado não ajuda a entender o aspecto econômico que está na base da globalização (na verdade, a fala da aluna 1 funciona como recapitulação, entretanto, os dados trazidos dizem respeito apenas à economia brasileira - e que faz as pessoas deixarem o

O trabalho com o oral público no ensino médio país - e não à mundial, que impulsionaria o êxodo das pessoas de seus países (como é o caso da Sìria e da Venezuela apresentado anteriormente).

O projeto que culminou com a apresentação do "trabalho de português" nos fornece indicativos do que envolve o trabalho com gêneros orais. Usamos os gêneros para agir no mundo social; por essa razão, eles jamais são usados isoladamente, eles sempre se interconectam com outros, formando uma grande rede de sentido. Se os gêneros, quando entram na escola, por um lado são usados para comunicar e, por outro, para ensinar, não é possível isolá-los da rede que ajudam a compor. Para construir, na escola, a situação mais próxima da realidade, o trabalho por projetos parece ser o mais adequado, porque ele preserva, em grande medida, as características do mundo social, em que tudo se interconecta.

Para chegar à apresentação oral, muitas ações foram necessárias: planejamento, pesquisa, tomada de decisão, escolha de imagens adequadas, colaboração, negociação, comunicação escrita e oral. Mesmo que as alunas tenham se valido do $\mathrm{CtrlC}+\mathrm{CtrlV}$, tão comum e preocupante na atualidade, percebe-se que houve apropriação do assunto que pesquisavam: em vários momentos a voz que se ouve é a delas, com propriedade. É tarefa do professor, pois, oferecer não só uma educação estética - em que entram as multissemioses que caracterizam os textos contemporâneos, mas um comportamento ético, em que a propriedade do outro é respeitada.

Apesar de faltar um slide que feche o raciocínio que vinham construindo por meio de palavras, gráficos e imagens, percebe-se a coesão e coerência internas, que podem ser observadas no uso de referentes, conectores e uso de vocabulário mais elaborado, cuja explicação 
Dorotea Frank

Kersch

Raquel Considerações finais

Gonçalves de

Oliveira

440 ampliar seus multiletramentos.

vão dando com o uso da realidade que lhes é próxima como exemplo. As alunas demonstram que compreenderam o que é o gênero, e o produziram adequando-se à situação em que se encontravam. $O$ gênero apresentação oral combina a leitura em voz alta com a fala monitorada. Ao terem de escolher as imagens que ajudassem a construir sentido em sua apresentação oral, as alunas tiveram, também, a oportunidade de

Os tempos atuais requerem que a escola desenvolva capacidades que deem conta das multissemioses, o que se precisa levar em conta quando se pensa em trabalhar gêneros orais públicos, que requerem fala monitorada. $O$ gênero apresentação oral, como se viu, se presta para esses objetivos em função de suas características multimodais (a escrita, a fala, imagens, até mesmo vídeos, cores e gráficos), usadas para a construção de sentido. É, portanto, um gênero bastante útil para desenvolver o domínio da oralidade.

Ao seguir algumas características do PDG, foi dada aos alunos a oportunidade de, antes da apresentação para o público em geral, fazer a apresentação para os colegas em sala de aula, analisar o vídeo dessa apresentação e fazer as correções necessárias, o que certamente levou aos resultados da produção oral final. Com a análise dos dados, se percebe que não existe um oral, mas uma mescla deles, ou um continuum, como já destacou Marcuschi (1997), que vai de um uso menos monitorado ou mais monitorado. No caso da apresentação oral, um gênero que é escrito/construído para ser apresentado, é possível observar desde uma leitura em voz alta dos slides, leitura/consulta a outros textos de apoio, até o improviso, em que exemplos são buscados de modo a manter a atenção da audiência. Em todos os momentos desse continuum, entretanto, o uso monitorado da linguagem oral pode ser observado.

Os tempos atuais requerem que os cidadãos saibam ler (e escrever) não apenas o impresso, mas também o digital e o imagético. Como professores de línguas, precisamos, acima de tudo, ajudar nossos alunos a pensar criativamente, a ser inovadores e a pensar por e sobre si mesmos, com o propósito de abrir novas possibilidades e restauração social (WOLK, 2003). 


\section{REFERÊNCIAS}

BARTON, D.; LEE, C. Linguagem online : textos e práticas digitais. Campinas: Parábola, 2015.

BRASIL. Parâmetros Curriculares Nacionais: $3^{\circ}$ e $4^{\circ}$ ciclos do Ensino Fundamental: Língua Portuguesa. Brasília/DF: MEC/SEF.BRASIL, 1998.

BRASIL. Base Nacional Comum Curricular-BNCC. Brasília: MEC, 2018.

DOLZ, J.; PASQUIER, A.; BRONCKART, J.-P. L'acquisition des discours: émergence d'une compétence ou apprentissage de capacités langagières? Études de Linguistique Appliquée, n. 102, p. 23-37, 1993.

O trabalho com o oral público no ensino médio

DOLZ, J. ; NOVERRAZ, M.; SCHNEUWLY, B. Sequências didáticas para o oral e a escrita: apresentação de um procedimento. In: SCHNEUWLY, B; DOLZ, J. Gêneros Orais e escritos na escola. Trad. e org. ROJO, R.; CORDEIRO, G. S. São Paulo: Mercado das Letras, 2004, p. 95-128.

GOULART, C. A caracterização do gênero exposição oral no contexto das práticas de linguagem na escola. Revista olhares e trilhas. Uberlândia, v.19, n.2, p. 236-264, Jul./ Dez., 2017.

GUIMARÃES, A.M.M.; KERSCH, D.F. (org.). Caminhos da construção: projetos didáticos de gênero no domínio do argumentar. $1^{\mathfrak{a}}$ ed., Campinas, Mercado de Letras, 2014.

GUIMARÃES, A.M.M.; KERSCH, D.F. E então... Caminhos da construção de projetos didáticos de gênero- da comunidade de indagação ao desenvolvimento de professoras(es) e das pesquisadoras. In: A.M.M. GUIMARÃES; A. CARNIN; D.F. KERSCH (org.), Caminhos da construção: reflexões sobre projetos didáticos de gênero. $1^{\text {a }}$ ed., Campinas, Mercado de Letras, 2015, vol. 3, p. 7-26.

KERSCH, D. F.; GUIMARÃES, A. M. M. A construção de projetos didáticos de leitura e escrita como resultado de uma proposta de formação continuada cooperativa. Revista Brasileira de Linguística Aplicada - RBLA, v. 12, n. 3, p. 533-556, 2012. 
KERSCH, D. F.; MARQUES, R. G. Leitura e escrita em Projeto Didático de Gênero: o uso de tecnologias e o desenvolvimento das capacidades de linguagem. v. 15, n. 1, p. 384-407, 2015.

KERSCH, D. F.; MARQUES, R. G. Redes sociais digitais na escola:

Dorotea Frank

Kersch

Raquel Gonçalves de

Oliveira possibilidades de conexão, produção de sentido e aprendizagem. Diálogo das Letras, Pau dos Ferros, v. 06, n. 02, p. 343-362, 2017.

KERSCH, D; LESLEY, M. Hosting and Healing: A Framework for Critical Media Literacy Pedagogy. Journal of Media Literacy Education. (a sair em dez. 2019)

MARCUSCHI, L.A. Da Fala para a Escrita: Atividades de Retextualização. São Paulo: Cortez, 1997

MARCUSCHI, Luiz Antônio. Fala e escrita. MARCUSCHI, Luiz Antônio; DIONÍSIO, Ângela Paiva (Org.) 1.ed. Belo Horizonte: Autêntica, 2007.

ROJO, R. Letramentos múltiplos, escola e inclusão social. São Paulo: Parábola Editorial, 2009.

ROJO, Roxane, SCHNEUWLY, Bernard. As relações oral/escrita nos gêneros orais formais e públicos: o caso da conferência acadêmica. Linguagem em (Dis)curso, vol. 6, no. 3, 2006, p. 463-493

SCHNEUWLY, B. Palavra e ficcionalização: um caminho para o ensino da linguagem oral. In: ROJO, R.; CORDEIRO, G. S. (Trad. e Org.). Gêneros orais e escritos na escola. Campinas, SP: Mercado de Letras, 2004.

TRIPP, D. Pesquisa-ação: uma introdução metodológica. Educação e Pesquisa, v. 31, n. 3, p. 443-466, 2005.

WOLK, S. Teaching for Critical Literacy in Social Studies. The Social Studies, v. 94, n. 3, p. 101-106, 2003. 